\title{
The Analysis of Biomechanical Properties of Proximal Femur after Implant Removal
}

\author{
Jae Hyuk Yang, ${ }^{1}$ Tae Gon Jung, ${ }^{2}$ Arjun Rupanagudi Honnurappa, ${ }^{1}$ Jae Min Cha, ${ }^{3}$ \\ Chang Hwa Ham, ${ }^{1}$ Tae Yoon Kim, ${ }^{4}$ and Seung Woo Suh ${ }^{1}$ \\ ${ }^{1}$ Scoliosis Research Institute, Department of Orthopedics, Korea University Medical College, Guro Hospital, Guro 2-dong, \\ Guro-gu, Seoul 152-703, Republic of Korea \\ ${ }^{2}$ Osong Medical Innovation Foundation, Medical Device Development Center, Cheongju 363-951, Republic of Korea \\ ${ }^{3}$ The Division of Biological Sciences at The University of Chicago, Undergraduate Class of 2014, \\ 5801 South Ellis Avenue Chicago, IL 60637, USA \\ ${ }^{4} J u n g-H w a$ Girls High School, San 105 Beomeo-4-dong Sunsung-gu, Daegu 706-819, Republic of Korea
}

Correspondence should be addressed to Seung Woo Suh; spine@korea.ac.kr

Received 20 January 2016; Revised 20 May 2016; Accepted 13 June 2016

Academic Editor: Luis Gracia

Copyright (C) 2016 Jae Hyuk Yang et al. This is an open access article distributed under the Creative Commons Attribution License, which permits unrestricted use, distribution, and reproduction in any medium, provided the original work is properly cited.

Introduction. To compare the biomechanical stability of the femur following the removal of proximal femoral nail antirotation (PFNA-II) and dynamic hip screw (DHS). Material and Methods. 56 paired cadaveric femurs were used as experimental and control groups. In the experimental group, PFNA-II and DHS were randomly inserted into femurs on both sides and then removed. Thereafter, compression load was applied until fracture occurred; biomechanical stability of the femurs and associated fracture patterns were studied. Results. The ultimate load and stiffness of the control group were $6227.8 \pm 1694.1 \mathrm{~N}$ and $990.5 \pm 99.8 \mathrm{~N} / \mathrm{mm}$, respectively. These were significantly higher than experimental group $(p=0.014,<0.001)$ following the removal of PFNA-II $(4085.6 \pm 1628.03 \mathrm{~N}$ and $656.3 \pm 155.3 \mathrm{~N} / \mathrm{mm})$ and DHS $(4001.9 \pm 1588.3 \mathrm{~N}$ and $656.3 \pm 155.3 \mathrm{~N} / \mathrm{mm})$. No statistical differences in these values were found between the 2 device groups $(p=0.84,0.71)$, regardless of age groups. However, fracture patterns were different between two devices, intertrochanteric and subtrochanteric fractures. Conclusions. Mechanical stability of the proximal femurs does not differ after the removal of 2 different of fixation devices regardless of the age. However, it was significantly lower compared to an intact femur. Different fracture patterns have been shown following the removal of different fixation devices as there are variations in the site of stress risers for individual implants.

\section{Introduction}

Fracture around the trochanteric region of the hip is one of the most common problems among the elderly and is a common cause of morbidity and mortality in this group $[1,2]$. The aim of treatment of these fractures is to restore the patient's ability to move and walk as soon as possible [3]. Surgery is the treatment of choice and a number of implants have been developed to treat these difficult fractures via fixation [3-5]. Among them, the dynamic hip screw (DHS), an extramedullary device, has been considered for number of years as the best device for treating intertrochanteric fractures $[6,7]$, while the intramedullary device, consisting of the Gamma nail with various modifications, was commonly used for unstable intertrochanteric fractures $[8,9]$. The Arbeitsgemeinschaft für Osteosynthesefragen (AO) Group modified the Gamma nail and developed the proximal femoral nail antirotation (PFNA-II) device in 2004, and it has been widely used since that time for almost all types of trochanteric fractures [3].

Generally, the implant used for fracture treatment (extramedullary or intramedullary devices) is not removed after proximal femoral fractures because such patients are older than patients with other types of fractures, and implant removal-related complications are more common $[10,11]$. Although implant removal in proximal femur fractures is debated and there are many reports on the disadvantages of the inserted implant in view of biomechanics, certain 
situations such as discomfort during activities of daily living, painful hardware, metal allergy, carcinogenicity, and metal detection demand implant removal following the union of fractures [12-14]. Surgeons should get prepared for the implant removal and anticipate implant specific complications, because bone defects caused by intra- and extramedullary fixation devices vary in locations, sizes, and numbers. PFNA-II as intramedullary nail can have main bone defect in greater trochanteric area for nail with one minor bone defect for locking screw on femur shaft. However, DHS as extramedullary device can have one main and two minor bone defects on subtrochanteric area for the lag and cortical screws, consecutively. Furthermore, with the increased life expectancy in the recent decades, more people preferred to get these implants removed because of the thigh pain, the stress-shielding effects of these devices, and psychological discomfort at the concept of an implant [15]. One study recommends the removal of implants that are expected to remain in place for $>5$ years or in patients aged $<60$ years who are expected to live for many more years [15]. However, few studies have investigated how removing an intramedullary or extramedullary device affects the biomechanical stability of the proximal femur.

This cadaveric study aimed (1) to compare the biomechanical stability of the proximal femur following PFNA-II and DHS removal by applying an axial compressive load to the femur in view of the ultimate load and stiffness, (2) to compare these biomechanical factors between those aged $>65$ and $<65$ years, and (3) to evaluate the fractures following implant removal.

\section{Materials and Methods}

2.1. Cadaveric Specimens. Twenty paired adult human cadaveric femurs from 10 men and 10 women were obtained from the Department of Anatomy for the study. The specimens were examined for hematologic, metabolic, metastatic, and other medical diseases and local pathologies, for example, previous fractures and tumorous conditions. This was accomplished based on a detailed medical history from the donor's medical records and anteroposterior radiographic views of the femurs. Five donors were excluded: 1 femoral neck fracture treated with bipolar hemiarthroplasty, 1 intertrochanteric fracture treated with DHS, 1 local bone tumor, and 2 cases of proximal femoral deformity due to an old malunited intertrochanteric fracture and coxa vara, respectively. Thus, the experimental group in the present study comprised 15 paired femurs $(n=30)$ from human cadavers (10 men and 5 women). The mean donor age, weight, and height were $69.7 \pm 12.7$ years, $61.3 \pm 10.4 \mathrm{~kg}$, and $169.9 \pm$ $8.15 \mathrm{~cm}$, respectively.

In the control group, intact femurs or femurs in completely healed state after implant removal were included, we used 6 paired adult human cadaveric femurs $(n=12)$. The mean donor age, weight, and height were $61.2 \pm 9.9$ years, $66.5 \pm 9.1 \mathrm{~kg}$, and $171.8 \pm 6.6 \mathrm{~cm}$, respectively. The same preexperimental examination procedures described for the experimental group were performed on all donated femurs in the control group.
2.2. Morphological Examination. All soft tissues and surrounding muscles were stripped off, and only the bony portion was used for the analysis. The diameters of the femoral head, neck, and shaft and neck-shaft angle were measured with digital calipers and a goniometer. Prior to mechanical testing, anteroposterior radiographs of each femur were obtained to ensure the absence of any deformities or pathological conditions. All images were examined closely using a Picture Archiving and Communications System (LG Infinity, Seoul, Korea) after digitalization.

2.3. Bone Mineral Density Measurement. A $15 \times 17 \times 30 \mathrm{~cm}$ acrylic container was used to measure bone mineral density (BMD). The container acts as a phantom box and simulates in vivo conditions around the femoral bone during BMD measurement $[16,17]$. The femur was placed in the container and fixed at about $15^{\circ}$ internal rotation and submerged in water to a height and width of $15 \mathrm{~cm}$ to simulate soft tissues on radiography. BMD was measured using dual energy $\mathrm{X}$-ray absorptiometry with a Lunar Prodigy scanner (GE Healthcare, Milwaukee, WI, USA). An experienced radiology technician performed these measurements, and the data were evaluated with Lunar Prodigy enCORE 2005 software (GE Healthcare). Areal BMD and bone mineral content were measured in the following 3 femoral regions: the neck, greater trochanter, and the whole proximal femur, as recommended by the International Society for Clinical Densitometry [2].

2.4. Bone Preparation. Each pair of paired femurs was randomly assigned to the PFNA-II or DHS group. One surgeon performed the surgical procedures according to the manufacturer's instructions under the image intensifier guidance in the respective groups.

In the PFNA-II group, the PFNA-II ${ }^{\circledR}$ device (Synthes, Geneva, Switzerland), which is composed of a nail and helical blade, was inserted and removed after fixation. The nail is $170 \mathrm{~mm}$ long, and the proximal and distal diameters are 16.5 and $9 \mathrm{~mm}$, respectively. The helical blade diameter is $10.3 \mathrm{~mm}$, and the cylindrical body diameter is $11.0 \mathrm{~mm}$. It was placed centrally within $25 \mathrm{~mm}$ from the tip of the head contour. Distally, one $4.9 \mathrm{~mm}$ locking static bolt was used.

The DHS was used for comparison with the biomechanical stability of the PFNA-II. The lag screw of the DHS ${ }^{\circledR}$ device (Synthes) is composed of a threaded head with $12.5 \mathrm{~mm}$ diameters and a cylindrical body $7.9 \mathrm{~mm}$ in diameter. It was inserted centrally with a tip-apex distance of $<25 \mathrm{~mm}$. The $4-$ hole DHS side plate with an $8.0 \mathrm{~mm}$ diameter barrel was fixed to the femur using two $4.5 \mathrm{~mm}$ diameters bicortical screws. While inserting the DHS, care was taken not to overdamage the lateral cortex needed for an exact experiment. After completing the procedure, radiographs were obtained to ensure that implant placement was correct.

2.5. Biomechanical Evaluation. Before the biomechanical experiment, the bone condition after implant removal was assumed as the worst biomechanical condition because there was no healing process such as callus formation or bone remodeling at the removal site. 

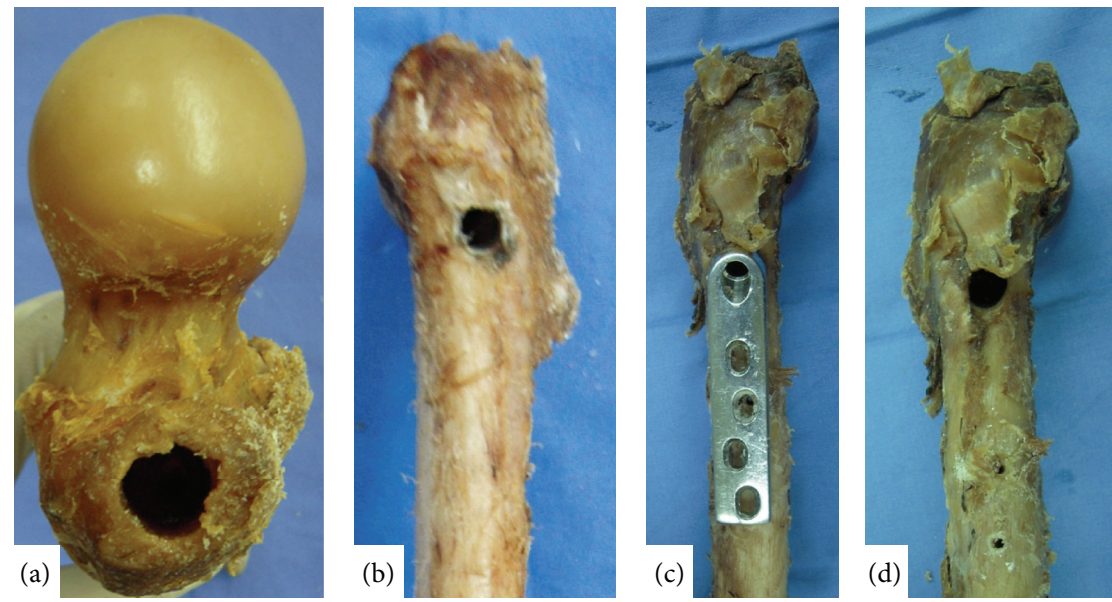

FIGURE 1: (a) An opening was created on the tip of the greater trochanter following removal of the PFNA-II (16.5 mm). (b) An opening was created on the lateral wall of the proximal femur following removal of the PFNA-II. (c) DHS position on the proximal femur. (d) An opening was created on the lateral wall of the proximal femur following removal of the DHS $(12.5 \mathrm{~mm})$.

All implants were removed on the day of testing (Figure 1). While removing the implant, care was taken not to cause extra disruption of the bone substance including the cortical and cancellous bone. Following implant removal, additional bone damage was reexamined through radiography. Specimens were removed from the study if breakage of the cortical bone at any portion of the femur or definitive injury of the cancellous bone on the calcar femorale or femoral neck area was found.

The distal condyle of the femur was resected and the shaft of the femur was placed vertically in a $20 \mathrm{~mm}$ metal tube using polymethylmethacrylate. During testing, each femur was held in a steel vise at $25^{\circ}$ adduction on the coronal plane and vertically on the sagittal plane, a position chosen to simulate the direction of force in the single-leg stance [18].

Each femur was subjected to a static compressive load acting vertically on the femoral head. The compression load was increased gradually in 25-N/sec increments using an 858 Mini Bionix ${ }^{\circledR}$ II test system (MTS System Corporation, Eden Prairie, MN, USA) [15]. The load and displacement curves were recorded at $1 \mathrm{~Hz}$ intervals.

Loading was continued until the occurrence of femoral failure. The failure load of the femur may have occurred after the achievement of ultimate load point, as there was a sudden decline in the load-displacement curve thereafter. We assumed that femoral failure had occurred beyond this point in the form of the construct, which could not maintain its anatomical frame under loading. Subsequently, the ultimate load and stiffness were measured and calculated in the loaddisplacement curve within the elastic region as the index of initial stability of the specimen was analyzed; additionally, the fracture pattern was morphologically and radiographically evaluated (Figures 2 and 3).

2.6. Statistical Analysis. Statistical analyses were performed using SPSS ${ }^{\circledR}$, version 13.0 (SPSS Inc., Chicago, IL, USA) for Windows ${ }^{\circledR}$. Data are reported as the mean \pm standard deviation. The Mann-Whitney $U$ and Kruskal-Wallis tests were used to compare nonparametric measures. A $p$ value $<0.05$ was considered statistically significant.

\section{Results}

\subsection{Experimental Group}

3.1.1. Morphologic Evaluation. The mean diameters of the femoral head, neck, and shaft were $4.69 \pm 0.30,3.2 \pm$ 0.40 , and $2.58 \pm 0.20 \mathrm{~cm}$, respectively. The neck-shaft angle was $133.53^{\circ} \pm 2.8^{\circ}$. Anatomically, there was no significant difference among the control, PFNA-II, and DHS groups. The detailed measurement values are described in Table 1.

3.1.2. BMD Measurement. The mean BMD of the neck, greater trochanter, and whole proximal femur was $0.67 \pm$ $0.18 \mathrm{mg} / \mathrm{cm}^{2}, 0.67 \pm 0.23 \mathrm{mg} / \mathrm{cm}^{2}$, and $1.16 \pm 1.39 \mathrm{mg} / \mathrm{cm}^{2}$, respectively. The mean BMD of the neck, greater trochanter, and whole proximal femur was also evaluated for the $<65$ and $>65$-year groups, and there was a significant difference $(p<0.001, p<0.001$, and $p=0.001)$ (Table 2$)$.

3.1.3. Biomechanical Evaluation. The mean ultimate load in the PFNA-II and DHS groups was 4085.6 $\pm 1628.03 \mathrm{~N}$ and $4001.9 \pm 1588.3 \mathrm{~N}$, respectively. There was no statistically significant difference in ultimate load between the 2 groups $(p=0.84)$ (Figure 4). Stiffness was $718.3 \pm 117.2 \mathrm{~N} / \mathrm{mm}$ and $656.3 \pm 155.3 \mathrm{~N} / \mathrm{mm}$ in the PFNA-II and DHS groups, respectively $(p=0.71)$. Based on age, the ultimate load and stiffness in the $>65$ - and <65-year groups were $3115.8 \pm 1182.6 \mathrm{~N}$ versus $5104.2 \pm 1300.3 \mathrm{~N}$, respectively $(p=0.002)$, and $675.1 \pm 158.5 \mathrm{~N} / \mathrm{mm}$ versus $641.1 \pm 116.8 \mathrm{~N} / \mathrm{mm}$, respectively $(p=0.22)$.

The ultimate load and stiffness of the PFNA-II and DHS groups according to the $>65$ - and $<65$-year groups were also analyzed and there was no significant difference between the PFNA-II and DHS groups (Table 2) (Figure 5). 


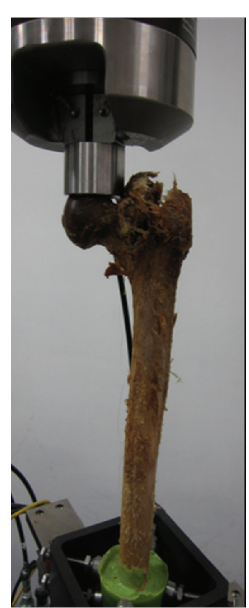

(a)

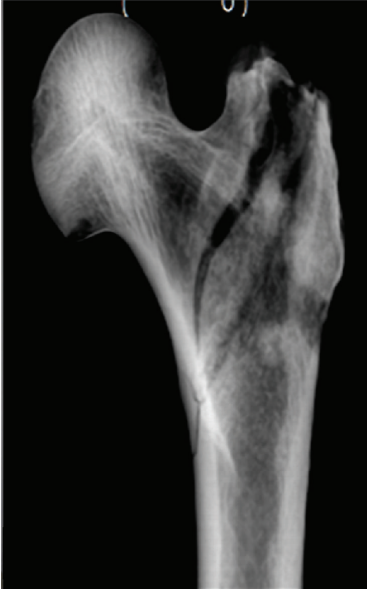

(b)

FIGURE 2: (a) Clinical photography of a fracture following application of a static axial compressive load to a femur from which a PFNA-II had been removed. (b) Anteroposterior radiograph of the proximal femur following PFNA-II removal revealing an intertrochanteric fracture.

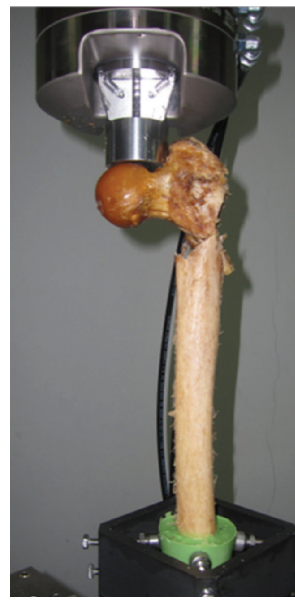

(a)

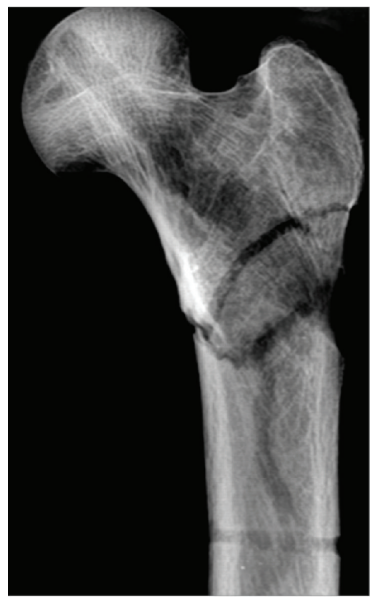

(b)

FIgURE 3: (a) Clinical photograph of a fracture following application of a static compression load to the specimen from which a DHS had been removed. (b) Anteroposterior radiograph of the proximal femur following DHS removal revealing a subtrochanteric fracture pattern. The step-off sign of lateral cortex of femur only observed on barrel hole.

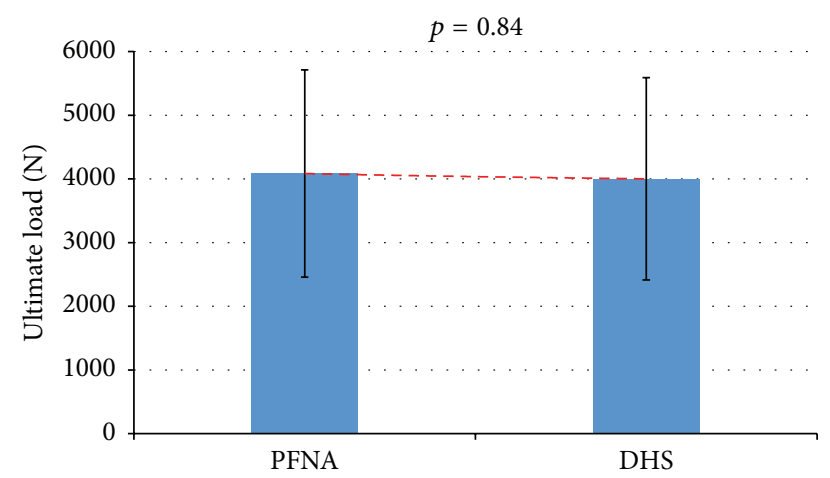

FIgure 4: No difference in ultimate load between PFNA-II and DHS groups $(p=0.84)$.

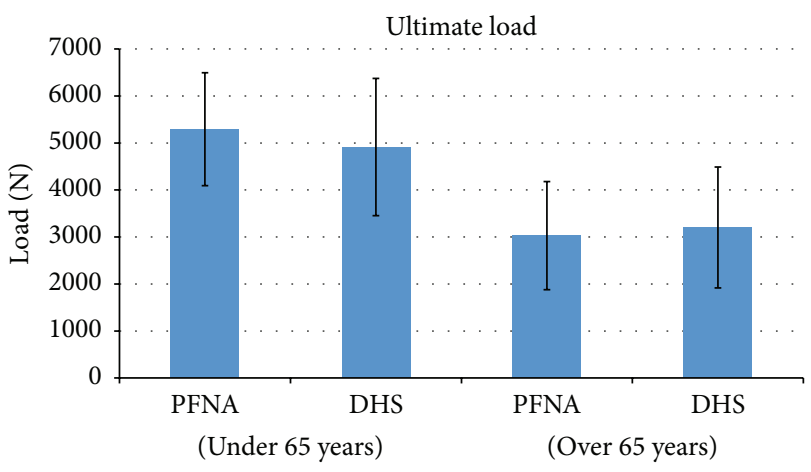

FIgURE 5: No difference in ultimate load between PFNA-II and DHS groups regardless of age ( $p=0.57,>65$ years; $p=0.81,<65$ years). 
TABLE 1: Anatomical, radiological, and biomechanical data of the PFNA-II and DHS groups.

\begin{tabular}{|c|c|c|c|c|}
\hline & \multirow{2}{*}{ Control group (intact femur) } & \multicolumn{2}{|c|}{ Experiment group } & \multirow{2}{*}{$p$ value } \\
\hline & & PFNA-II group & DHS group & \\
\hline \multicolumn{5}{|l|}{ (1) Anatomical factors } \\
\hline Femoral head diameter $(\mathrm{cm})$ & $4.8 \pm 0.3$ & $4.69 \pm 0.30$ & $4.70 \pm 0.32$ & 0.874 \\
\hline Femoral neck diameter $(\mathrm{cm})$ & $3.2 \pm 0.2$ & $3.20 \pm 0.43$ & $3.22 \pm 0.39$ & 0.395 \\
\hline Shaft diameter $(\mathrm{cm})$ & $2.6 \pm 0.1$ & $2.57 \pm 0.20$ & $2.60 \pm 0.21$ & 0.910 \\
\hline Neck-shaft angle $\left({ }^{\circ}\right)$ & $132.6 \pm 1.8$ & $133.93 \pm 2.25$ & $133.13 \pm 3.29$ & 0.395 \\
\hline \multicolumn{5}{|l|}{ (2) Radiological factors } \\
\hline BMD of the whole femur $\left(\mathrm{mg} / \mathrm{cm}^{2}\right)$ & $1.1 \pm 0.2$ & $0.94 \pm 0.25$ & $1.39 \pm 1.97$ & 0.182 \\
\hline $\mathrm{BMD}$ of the greater trochanter $\left(\mathrm{mg} / \mathrm{cm}^{2}\right)$ & $0.7 \pm 0.2$ & $0.67 \pm 0.22$ & $0.67 \pm 0.25$ & 0.738 \\
\hline BMD of the neck $\left(\mathrm{mg} / \mathrm{cm}^{2}\right)$ & $0.7 \pm 0.2$ & $0.68 \pm 0.18$ & $0.67 \pm 0.20$ & 0.67 \\
\hline \multicolumn{5}{|l|}{ (3) Biomechanical factors } \\
\hline Ultimate load (N) & $6227.8 \pm 1694.1$ & $4085.6 \pm 1628.03$ & $4001.9 \pm 1588.3$ & 0.014 \\
\hline Stiffness $(\mathrm{N} / \mathrm{mm})$ & $990.5 \pm 99.8$ & $718.3 \pm 117.2$ & $656.3 \pm 155.3$ & $<0.001$ \\
\hline
\end{tabular}

${ }^{\dagger}$ For statistical analysis Kruskal-Wallis test was used and $p$ values under 0.05 are considered significant.

The values were described as mean \pm standard deviation.

DHS and PFNA-II mean dynamic hip screw and proximal femoral nail antirotation.

$\mathrm{N}, \mathrm{cm},\left(^{\circ}\right)$, and mg mean newton, centimeter, degree, and milligram.

3.1.4. Fracture Patterns. Morphological and radiographic analyses of the PFNA-II group proximal femurs revealed a fracture line that passed from the tip of the greater trochanter near the entry point of the nail, exiting just below the lesser trochanter (long oblique type) in all cases (Figure 2(b)). In the DHS group, the fracture line passed from just below the entry point in the lateral cortex of the femur and extended well below the level of the lesser trochanter (transverse or reverse oblique type) in all cases (Figure 3(b)).

\subsection{Control Group}

3.2.1. Morphologic Evaluation. The morphological factors measured in experimental group were also measured in the control group and the detailed measurement values are described in Table 1.

3.2.2. BMD Measurement. The BMD factors measured in the experimental group were also measured in the control group; the detailed measurement values are described in Table 1. There was no significant difference among the control, PFNAII, and DHS groups.

3.2.3. Biomechanical Evaluation. The ultimate load and stiffness of the control group were measured and described in Table 1. The measurements for the $>65$ - and $<65$-year subgroups are described in Table 2.

3.2.4. Fracture Patterns. Morphological and radiographic analyses of all control group proximal femurs revealed various fracture lines around the femoral neck. All fracture lines were located within the femoral neck area (Figure 6).

\section{Discussion}

The implants used to repair fractures around the proximal femur are reported to be a source of pain following fracture union [19]. Many studies report the occurrence of discomfort due to implant, which can affect activity of daily living in around $10-40 \%$ patients $[12,13,19-25]$. These kinds of discomfort can lead to implant removal. However, considering the need of physical activities and comorbidities following it, implant removal has been reserved to younger patients. Nowadays due to extended life expectancy and the promotion of sports activities in old age, the need for implant removal has become a growing trend in elderly patients. In fact, Gardenbroek et al. found that persistent discomfort following PFN implantation in patients aged $>70$ years prompted removal in $6.8 \%$ of patients with simple PFN implantation and in $4.3 \%$ of patients with PFNA-II implantation [21]. Therefore, the surgeon should consider the biomechanical change to the femur following implant removal and possible complications according to the implant used.

In this study, biomechanical testing was performed using a position closely simulating a single-leg stance with a static compression load, which reflect mid-stance phase of walking in which stress on the femur is concentrated [26, 27]. The maximum loads allowed for the experimental group were much higher than the force experienced by the hip joint, which is approximately $3000 \mathrm{~N}$ in an average-build, $70 \mathrm{~kg}$ man (Table 1). On comparing these results with the control group data, which exhibited no statistically significant difference from the experimental groups anatomically or radiologically (i.e., BMD), the ultimate load for fracture and stiffness for initial stability without fracture were significantly lower $(p=0.014, p<0.001)$, but the mean values of the experimental groups were still $>3000 \mathrm{~N}$ (Table 1). This 
TABLE 2: Radiological and biomechanical data between the specimen over and under 65 years.

\begin{tabular}{|c|c|c|c|c|c|c|c|}
\hline & \multicolumn{2}{|c|}{ Control group } & \multicolumn{5}{|c|}{ Experimental group } \\
\hline & $\begin{array}{l}\text { Over } 65 \text { years } \\
\quad(n=6)\end{array}$ & $\begin{array}{c}\text { Under } 65 \\
\text { years }(n=6)\end{array}$ & \multicolumn{2}{|c|}{ Over 65 years $(n=16)$} & \multicolumn{2}{|c|}{ Under 65 years $(n=14)$} & $p$ values $^{\dagger}$ \\
\hline Age (year) & $70.0 \pm 1.4$ & $52.4 \pm 3.6$ & \multicolumn{2}{|c|}{$78.7 \pm 10.3$} & \multicolumn{2}{|c|}{$59.4 \pm 4.8$} & $\begin{array}{c}0.376 \text { (Over } 65 \text { years) } \\
0.067 \text { (Under } 65 \text { years) }\end{array}$ \\
\hline \multicolumn{8}{|l|}{$\begin{array}{l}\text { (1) Radiological } \\
\text { factors }\end{array}$} \\
\hline $\begin{array}{l}\text { BMD of the neck } \\
\left(\mathrm{mg} / \mathrm{cm}^{2}\right)\end{array}$ & $0.6 \pm 0.1$ & $0.9 \pm 0.1$ & \multicolumn{2}{|c|}{$0.54 \pm 0.14$} & \multicolumn{2}{|c|}{$0.83 \pm 0.10$} & $\begin{array}{c}0.494 \text { (Over } 65 \text { years) } \\
0.201 \text { (Under } 65 \text { years) }\end{array}$ \\
\hline $\begin{array}{l}\text { BMD of the greater } \\
\text { trochanter } \\
\left(\mathrm{mg} / \mathrm{cm}^{2}\right)\end{array}$ & $0.6 \pm 0.1$ & $0.9 \pm 0.1$ & \multicolumn{2}{|c|}{$0.49 \pm 0.15$} & \multicolumn{2}{|c|}{$0.87 \pm 0.11$} & $\begin{array}{c}0.178 \text { (Over } 65 \text { years) } \\
0.841 \text { (Under } 65 \text { years) }\end{array}$ \\
\hline $\begin{array}{l}\text { BMD of the whole } \\
\text { femur }\left(\mathrm{mg} / \mathrm{cm}^{2}\right)\end{array}$ & $1.0 \pm 0.1$ & $1.2 \pm 0.1$ & \multicolumn{2}{|c|}{$1.23 \pm 1.93$} & \multicolumn{2}{|c|}{$1.09 \pm 0.17$} & $\begin{array}{c}0.90 \text { (Over } 65 \text { years) } \\
0.109 \text { (Under } 65 \text { years) }\end{array}$ \\
\hline \multicolumn{8}{|l|}{$\begin{array}{l}\text { (2) Biomechanical } \\
\text { factors }\end{array}$} \\
\hline Ultimate load (N) & $\begin{array}{l}4742.7 \pm \\
758.5\end{array}$ & $7712.8 \pm 667.9$ & $3115.8 \pm$ & 1182.6 & $5104.2 \pm$ & 1300.3 & $\begin{array}{c}0.027 \text { (Over } 65 \text { years) } \\
0.001 \text { (Under } 65 \text { years) }\end{array}$ \\
\hline \multirow[t]{2}{*}{ Stiffness (N/mm) } & $920.2 \pm 52.4$ & $1060.8 \pm 82.5$ & \multicolumn{2}{|c|}{$675.1 \pm 158.5$} & \multicolumn{2}{|c|}{$641.1 \pm 116.8$} & $\begin{array}{c}0.002 \text { (Over } 65 \text { years) } \\
0.012 \text { (Under } 65 \text { years) }\end{array}$ \\
\hline & & & PFNA $(n=8)$ & DHS $(n=8)$ & PFNA $(n=7)$ & DHS $(n=7)$ & $p$ values ${ }^{\ddagger}$ \\
\hline Ultimate load (N) & & & $\begin{array}{l}3028.6 \pm \\
1151.3\end{array}$ & $\begin{array}{c}3203.1 \pm \\
1286.1\end{array}$ & $\begin{array}{c}5293.7 \pm \\
1202.3\end{array}$ & $\begin{array}{c}4914.8 \pm \\
1460.8\end{array}$ & $\begin{array}{c}0.57 \text { (Over } 65 \text { years) } \\
0.81 \text { (Under } 65 \text { years) }\end{array}$ \\
\hline Stiffness (N/mm) & & & $672.2 \pm 121.3$ & $675.1 \pm 158.5$ & $770.9 \pm 94.0$ & $641 \pm 116.8$ & $\begin{array}{c}0.96 \text { (Over } 65 \text { years) } \\
0.54 \text { (Under } 65 \text { years) }\end{array}$ \\
\hline
\end{tabular}

${ }^{\dagger}$ For statistical analysis Mann-Whitney $U$ test was used and $p$ values under 0.05 were considered to be significant. The age, radiological factors, and biomechanical factors between control and experimental group were compared and analyzed statistically according to aged group.

${ }^{\ddagger}$ For statistical analysis Mann-Whitney $U$ test was used and $p$ values under 0.05 were considered to be significant. Only PFNA and DHS subgroups over and under 65 years in experimental group were analyzed statistically.

The values were described as mean \pm standard deviation.

Data were reported as mean (standard deviation (SD)).

DHS: dynamic hip screw.

PFNA-II: proximal femoral nail antirotation.

$\mathrm{N}$ : newton.

$\mathrm{cm}$ : centimeter.

o: degree.

mg: milligram.

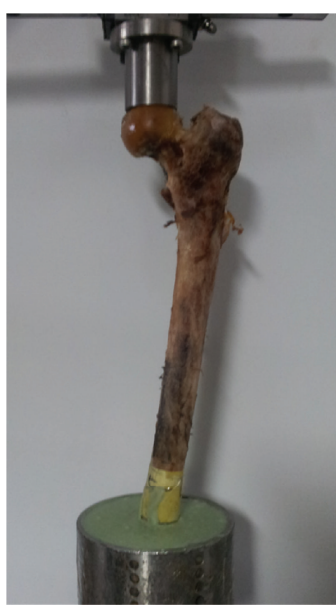

(a)

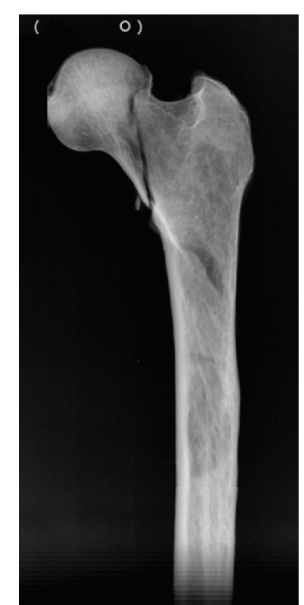

(b)

Figure 6: (a) Clinical photograph of a fracture following application of a static compression load to a specimen that did not undergo any procedures (control group). (b) Anteroposterior radiograph of the proximal femur revealing a femoral neck fracture. 
means that although fracture cannot occur in a single-leg stance state, the femur from which the implant was removed is thought to be structurally weak before the healing is complete.

To identify the effect of the aging process on bone quality change, the ultimate load and stiffness of proximal femur were measured in accordance with the ages of $>65$ and $<65$ years (Table 2). The femurs were equally good at tolerating normal weight-bearing loads following implant removal regardless of implant type and age. However, some $>65$-year specimens $(n=11 / 16)$ had failure loads of $<3000 \mathrm{~N}$, and these values were significantly less than that of the control group ( $>4000 \mathrm{~N} ; p=0.027$ ). Stiffness was not affected by the age in control and experimental groups. The cause of this phenomenon is thought to be the preservation of cortical bone, which acts as the main stabilizer of the femur, and the change in the diameter of the femur from the aging process. However stiffness in the $>65$ and $<65$ years was statistically decreased following implant removal due to cortical breakage of the femur, demonstrating structural weakness $(p=0.002$, $p=0.012$ ). Based on these results, we suggest that more care is needed for patients aged $>65$ years following implant removal, and if implant removal should be performed in patients of this age group due to painful hardware or thigh pain by stress concentration around the implant, mismatch augmentation of the subsequent bone defect with bone cement or refixation with small or matched implants should be considered. Moreover, based on the hypothesis that an intact femur is similar to a completely healed state following implant removal despite some limitations, the surgeon should practice with more caution regarding early-stage implant removal due to the lower load-bearing capacity of the healed femur.

There were no statistically significant differences between the PFNA-II and DHS groups for ultimate loads and stiffness $(p=0.838, p=0.713$ ) (Figure 4). This result differed from our expectations and from the results of a previous study that compared femur biomechanics following Gamma nail and DHS removal [28]. In a study by Kukla et al. [28], authors concluded that the failure load required to create a fracture in the cadaveric femur was higher for femurs from which a DHS implant was removed than for femurs from which a Gamma nail was removed. The discrepancy between previous findings and our study may be due to differences in the design of PFNA-II devices and the Gamma nail. The standard Gamma nail (SGN) used in the previous study was a first-generation device. Thus, the proximal and distal shaft diameters of the SGN are $17 \mathrm{~mm}$ and $12 \mathrm{~mm}$, respectively, and the shaft of the SGN has a medial-lateral bending angle (M-L angle) of $10^{\circ}$. In contrast, the proximal and distal diameters of the PFNA-II are $16.5 \mathrm{~mm}$ and $9 \mathrm{~mm}$, respectively, and the $\mathrm{M}-\mathrm{L}$ angle is $5^{\circ}$. Due to these differences, the SGN created more extensive bone loss in the proximal femur than the PFNA-II in our study, more excessive stress was concentrated in the removal region of the nail because of the large shaft diameter and the excessive M-L angle of the SGN [29]. This resulted in relatively lower fracture loads in the SGN group in the previous study than in the PFNA-II group in the present study. We also compared PFNA-II and DHS in the $>65$ and $<65$-year groups. There was also no significant difference (Figure 5); conclusively, PFNA-II and DHS removal does not affect femur stability regardless of age. We believe that the possible cause is the minimal breakage of the lateral cortex and calcar femorale by PFNA-II due to design improvements.

Regarding fracture patterns, long, oblique-type intertrochanteric fractures were observed in the PFNA-II group, whereas transverse or reverse oblique-type subtrochanteric fractures were observed in the DHS group. The opening created by the PFNA-II on the tip of the greater trochanter may act as the starting point of a crack that propagates along the intertrochanteric line to cause intertrochanteric fractures, and opening the lateral wall of the femur with the DHS may increase stress, leading to fractures. These fracture patterns corresponded with our preexperimental expectations, although they differed from those reported by a previous biomechanical study [28].

In a study by Kukla et al., the fracture pattern of the SGN removal group was complicated: an intertrochanteric fracture with or without femoral neck fracture; however, only simple intertrochanteric fractures were observed in the PFNA-II group in our study. These differing fracture patterns between intramedullary devices may have been due to differences in the size and design of inserted devices and anatomical difference of enrolled cadaveric femurs [26, 27]. Firstly, the PFNA-II helical blade diameter was from $10.3 \mathrm{~mm}$ (anterior to mid body) to $11.0 \mathrm{~mm}$ (mid to posterior), while, for the SGN, the lag screw diameter on the threaded portion, namely, the head of the lag screw, was $12 \mathrm{~mm}$. Therefore, if the helical blade and lag screw were inserted and removed along the lateral wall to the femoral head, there would be much greater bone loss in the SGN group as compared to our PFNA-II group. In particular, the bone loss ratio would be much higher in the femoral neck because anatomically this area is the narrowest zone of the proximal femur [30,31]. Assuming that the femoral neck has a truly round shape, the ratio of bone loss at the narrowest point of the femoral neck can be calculated as $\pi \times$ (blade or lag screw diameter $/ 2)^{2}$ to $\pi \times$ (femoral neck diameter $/ 2)^{2}$. According to this method, the percentage ratios of bone loss were $10.7 \pm 2.5 \%$ and $14.5 \pm 3.4 \%$ for PFNA-II and SGN, respectively, based on our data for the neck diameters of the specimens. There is a significant difference between these values ( $p=0.04)$. Therefore, only simple intertrochanteric fractures were observed in our study. Secondly, femoral neck length in Asian population is shorter and anteversion is larger than Caucasians [32]. This difference of geometry in proximal femur such as length, anteversion, and cortical width of femoral head-neck can cause the different stress condition on femur neck and intertrochanteric area during compression load test. Considering the importance of bioequivalence controlled laboratory environment, abovementioned anatomical difference can cause difference in fracture patterns after PFNA-II and SGN removal.

The fracture pattern observed in the DHS group also differed from that of previous studies. Kukla et al. observed femoral neck fractures in their DHS group; however, we observed subtrochanteric fractures in our study [28]. We inferred that this might be due to implant design and anatomical difference of enrolled cadaveric femurs [33,34]. Firstly, in 
the previous study, the opening of the lateral wall was $12 \mathrm{~mm}$ and the study was performed in $12^{\circ}$ adduction. However, the opening of the lateral wall in our study was $12.5 \mathrm{~mm}$ due to the head size of the lag screw, and the biomechanical study was performed in $25^{\circ}$ of adduction [28]. When the adduction angle is increased, the compression force on the femoral head acts more vertically on the femoral neck area. Consequently, the neck portion is more resistant to compression force. However, the compression force is more concentrated around the greater to lesser trochanteric area because this is the apex of the femur in the coronal plane. Accordingly, this area becomes vulnerable to fracture. Compared to the previous study, the larger opening on the lateral wall of the femur and the adducted position in our study may have led to fracture of the subtrochanteric area instead of the femoral neck. Thirdly, due to anatomical variation between Asians and Caucasians, mismatch between implant and femoral geometry is possible as PFNA-II and DHS implants were designed based on the data of Caucasian femurs. This mismatch can also give structural damages on the femur, which can be a possible cause of different fracture patterns between this and previous studies.

From a clinical perspective, patients who undergo PFNAII removal may have more surgically amenable fractures (intertrochanteric fracture) compared to patients who undergo DHS removal (subtrochanteric fractures) because surgical treatment of an intertrochanteric fracture is relatively easier and has fewer complications than that for a subtrochanteric fracture.

This study had certain limitations. (1) The load exerted on the femur was a simple compressive force (especially the axial loading, considering simplicity, limited availability of cadavers, and reproducibility of experimental design) in this experimental study. Therefore, various types of force that may act on femur could not be verified. (2) Despite the various intramedullary and extramedullary implants available to orthopedic surgeons; we compared only one type of each extramedullary and intramedullary device. (3) We performed this study using anatomically normal cadaveric femurs without the fracture healing process; therefore, morphological changes during fracture healing, for example, callus formation, remodeling, subtle malreduction, and femoral neck shortening, could not be evaluated. (4) The behavior of the devices inside a femur of living person with bone growth or bone healing process cannot be anticipated nor explained. Therefore, the final state of the femur after removing the device could not be accounted in this study as it can vary according to the patients' healing conditions. (5) The anatomical variation among races was not considered in this study. There are anatomical differences in structure of proximal femur between different races. This difference can affect the fracture pattern and complications after implant removal depending on races [35].

However, considering the limitation of preparing a large number of cadaveric femurs for research in various conditions and the difficulty of obtaining a statistically meaningful number of fused cadaveric femurs with various anatomical deformations following proximal femur fracture, our study design may be considered appropriate as an initial study that sheds some light on a developing medical topic. Additionally, a test applying compression load on the intact femur was carried out. Therefore, a comparative analysis of the stiffness variation of the femur neck after implant removal was possible. Also, using this data, the difference in the effect between the intra- and extramedullary implant on femur neck after its removal could be verified.

In conclusion, our results indicate that the ultimate load and stiffness following the removal of an intramedullary nail device (PFNA-II) by static compression load are similar to that of a conventional extramedullary fixation device (DHS) regardless of age. Based on these results, we may assume that the widely used recent intramedullary nail devices (PFNAII) are as safe as extramedullary devices (DHS) in early-stage conditions without callus formation or bone remodeling following implant removal. However, because the failure load in $>65$-year femurs $(11 / 16)$ could be lower than the acceptable ultimate load $(3000 \mathrm{~N})$, care is necessary when treating patients with early-stage removal of different implant types, also considering fracture patterns that differ based on the type of device removed. Considering the limitations of the present study such as various anatomical variations in cadaveric femurs and simulation study using finite element method to assure the conclusion of this study, comparison of multiple implant types, fresh cadaveric tests, biomechanical testing involving multiple-type loads, and repeated-stress fatigue testing should be carried out to confirm biomechanical stability following the removal of an intramedullary nail device.

\section{Disclosure}

The authors confirm that all of them approved the order of authors listed in the paper. There was not any involvement of the Ministry of Health, Welfare \& Family Affairs, in any part of this research.

\section{Competing Interests}

The authors confirm that there are no known competing interests associated with this publication and there has been no significant financial support for this work that could have influenced its outcome.

\section{Acknowledgments}

This study was supported by a grant of the Korea Healthcare Technology R\&D project, Ministry for Health, Welfare \& Family Affairs, Republic of Korea (A110416). The authors would like to thank the Ministry of Health, Welfare \& Family Affairs, for allowing them to perform this research.

\section{References}

[1] G. B. Aharonoff, K. J. Koval, M. L. Skovron, and J. D. Zuckerman, "Hip fractures in the elderly: predictors of one year mortality," Journal of Orthopaedic Trauma, vol. 11, no. 3, pp. 162165, 1997.

[2] R. E. Cole, "Improving clinical decisions for women at risk of osteoporosis: dual-femur bone mineral density testing," Journal 
of the American Osteopathic Association, vol. 108, no. 6, pp. 289295, 2008.

[3] J. Windolf, D. A. Hollander, M. Hakimi, and W. Linhart, "Pitfalls and complications in the use of the proximal femoral nail," Langenbeck's Archives of Surgery, vol. 390, no. 1, pp. 59-65, 2005.

[4] J. A. Bendo, L. S. Weiner, E. Strauss, and E. Yang, "Collapse of intertrochanteric hip fractures fixed with sliding screws," Orthopaedic Review, pp. 30-37, 1994.

[5] J. J. Bonamo and A. B. Accettola, "Treatment of intertrochanteric fractures with a sliding nail-plate," Journal of Trauma, vol. 22, no. 3, pp. 205-215, 1982.

[6] S. Eberle, C. Wutte, C. Bauer, G. von Oldenburg, and P. Augat, "Should extramedullary fixations for hip fractures be removed after bone union?” Clinical Biomechanics, vol. 26, no. 4, pp. 410414, 2011.

[7] T. N. Joseph, A. L. Chen, F. J. Kummer, and K. J. Koval, "The effect of posterior sag on the fixation stability of intertrochanteric hip fractures," Journal of Trauma-Injury, Infection and Critical Care, vol. 52, no. 3, pp. 544-547, 2002.

[8] S. F. Rosenblum, J. D. Zuckerman, F. J. Kummer, and B. S. Tam, "A biomechanical evaluation of the gamma nail," The Journal of Bone \& Joint Surgery - British Volume, vol. 74, no. 3, pp. 352-357, 1992.

[9] M. J. Parker and H. H. G. Handoll, "Gamma and other cephalocondylic intramedullary nails versus extramedullary implants for extracapsular hip fractures in adults," Cochrane Database of Systematic Reviews, no. 3, Article ID CD000093, 2008.

[10] T. O. Boerger, G. Patel, and J. P. Murphy, "Is routine removal of intramedullary nails justified," Injury, vol. 30, no. 2, pp. 79-81, 1999.

[11] M. L. Busam, R. J. Esther, and W. T. Obremskey, "Hardware removal: indications and expectations," Journal of the American Academy of Orthopaedic Surgeons, vol. 14, no. 2, pp. 113-120, 2006.

[12] W. Lehmann, M. Rupprecht, J. Nuechtern et al., "What is the risk of stress risers for interprosthetic fractures of the femur? A biomechanical analysis," International Orthopaedics, vol. 36, no. 12, pp. 2441-2446, 2012.

[13] J.-S. Pu, L. Liu, G.-L. Wang, Y. Fang, and T.-F. Yang, "Results of the proximal femoral nail anti-rotation (PFNA) in elderly Chinese patients," International Orthopaedics, vol. 33, no. 5, pp. 1441-1444, 2009.

[14] S. Eberle, C. Wutte, C. Bauer, G. Von Oldenburg, and P. Augat, "Should extramedullary fixations for hip fractures be removed after bone union?” Clinical Biomechanics, vol. 26, no. 4, pp. 410414, 2011.

[15] R. Burge, B. Dawson-Hughes, D. H. Solomon, J. B. Wong, A. King, and A. Tosteson, "Incidence and economic burden of osteoporosis-related fractures in the United States, 2005-2025," Journal of Bone and Mineral Research, vol. 22, no. 3, pp. 465-475, 2007.

[16] B. S. Myers, K. B. Arbogast, B. Lobaugh, K. D. Harper, W. J. Richardson, and M. K. Drezner, "Improved assessment of lumbar vertebral body strength using supine lateral dual-energy X-ray absorptiometry," Journal of Bone and Mineral Research, vol. 9, no. 5, pp. 687-693, 1994.

[17] C. Djokoto, G. Tomlinson, S. Waldman, M. Grynpas, and A. M. Cheung, "Relationship among MRTA, DXA, and QUS," Journal of Clinical Densitometry, vol. 7, no. 4, pp. 448-456, 2004.
[18] M. N. Mahomed, I. J. Harrington, and T. C. Hearn, "Biomechanical analysis of the Medoff sliding plate," The Journal of Trauma, vol. 48, no. 1, pp. 93-100, 2000.

[19] M. J. Parker and H. H. Handoll, "Gamma and other cephalocondylic intramedullary nails versus extramedullary implants for extracapsular hip fractures in adults," Cochrane Database of Systematic Reviews, no. 9, Article ID CD000093, 2010.

[20] V. Filardi and R. Montanini, "Measurement of local strains induced into the femur by trochanteric Gamma nail implants with one or two distal screws," Medical Engineering \& Physics, vol. 29, no. 1, pp. 38-47, 2007.

[21] T. J. Gardenbroek, M. J. M. Segers, R. K. J. Simmermacher, and E. R. Hammacher, "The proximal femur nail antirotation: an identifiable improvement in the treatment of unstable pertrochanteric fractures?" Journal of Trauma-Injury, Infection and Critical Care, vol. 71, no. 1, pp. 169-174, 2011.

[22] K. S. Leung, P. Procter, B. Robioneck, and K. Behrens, "Geometric mismatch of the gamma nail to the Chinese femur," Clinical Orthopaedics and Related Research, no. 323, pp. 42-48, 1996.

[23] F. Chevalley and D. Gamba, "Gamma nailing of pertrochanteric and subtrochanteric fractures: clinical results of a series of 63 consecutive cases," Journal of Orthopaedic Trauma, vol. 11, no. 6, pp. 412-415, 1997.

[24] P. R. Goldhagen, D. R. O'Connor, D. Schwarze, and E. Schwartz, "A prospective comparative study of the compression hip screw and the gamma nail," Journal of Orthopaedic Trauma, vol. 8, no. 5, pp. 367-372, 1994.

[25] P. C. Noble, J. W. Alexander, L. J. Lindahl, D. T. Yew, W. M. Granberry, and H. S. Tullos, "The anatomic basis of femoral component design," Clinical Orthopaedics and Related Research, no. 235, pp. 148-165, 1988.

[26] J. Richmond, G. B. Aharonoff, J. D. Zuckerman, and K. J. Koval, "Mortality risk after hip fracture," Journal of Orthopaedic Trauma, vol. 17, no. 1, pp. 53-56, 2003.

[27] J. Zou, Y. Xu, and H. Yang, "A comparison of proximal femoral nail antirotation and dynamic hip screw devices in trochanteric fractures," Journal of International Medical Research, vol. 37, no. 4, pp. 1057-1064, 2009.

[28] C. Kukla, W. Pichl, R. Prokesch et al., "Femoral neck fracture after removal of the standard gamma interlocking nail: a cadaveric study to determine factors influencing the biomechanical properties of the proximal femur," Journal of Biomechanics, vol. 34, no. 12, pp. 1519-1526, 2001.

[29] P. J. Radford, M. Needoff, and J. K. Webb, "A prospective randomised comparison of the dynamic hip screw and the gamma locking nail," The Journal of Bone \& Joint SurgeryBritish Volume, vol. 75, no. 5, pp. 789-793, 1993.

[30] H. Gray, S. Standring, H. Ellis, and B. K. B. Berkovitz, Gray's Anatomy: The Anatomical Basis of Clinical Practice, Elsevier/Churchill Livingstone, New York, NY, USA, 39th edition, 2005.

[31] C. Rosse, P. Gaddum-Rosse, and W. H. Hollinshead, Hollinshead's Textbook of Anatomy, vol. 5th, Lippincott-Raven, Philadelphia, Pa, USA, 1997.

[32] F. T. Hoaglund and W. D. Low, "Anatomy of the femoral neck and head, with comparative data from Caucasians and Hong Kong Chinese," Clinical Orthopaedics and Related Research, no. 152, pp. 10-16, 1980.

[33] W. E. Bacon, S. Maggi, A. Looker et al., "International comparison of hip fracture rates in 1988-89," Osteoporosis International, vol. 6, no. 1, pp. 69-75, 1996. 
[34] A. K. Mishra, P. Chalise, R. P. Singh, and R. K. Shah, "The proximal femur-a second look at rational of implant design," Nepal Medical College Journal, vol. 11, no. 4, pp. 278-280, 2009.

[35] L. M. Marshall, J. M. Zmuda, B. K. S. Chan et al., "Race and ethnic variation in proximal femur structure and BMD among older men," Journal of Bone and Mineral Research, vol. 23, no. 1, pp. 121-130, 2008. 


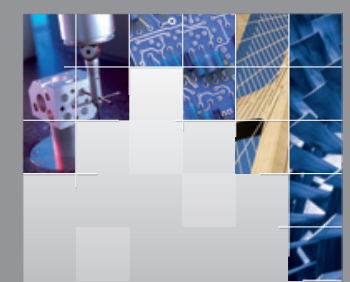

\section{Enfincering}
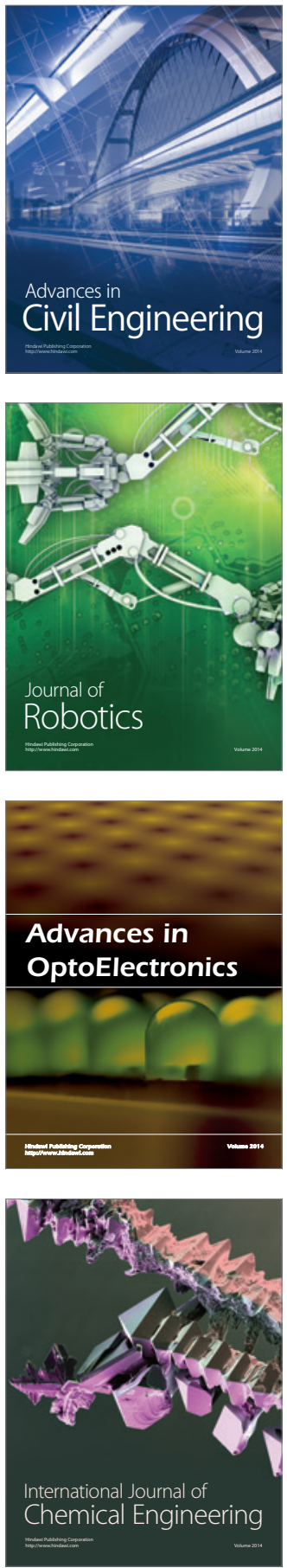

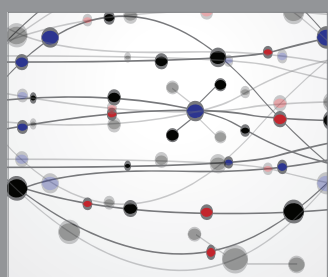

The Scientific World Journal

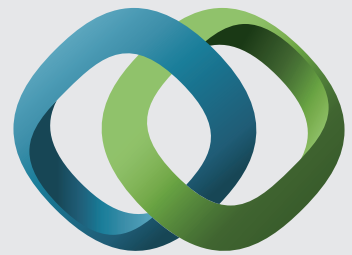

\section{Hindawi}

Submit your manuscripts at

http://www.hindawi.com
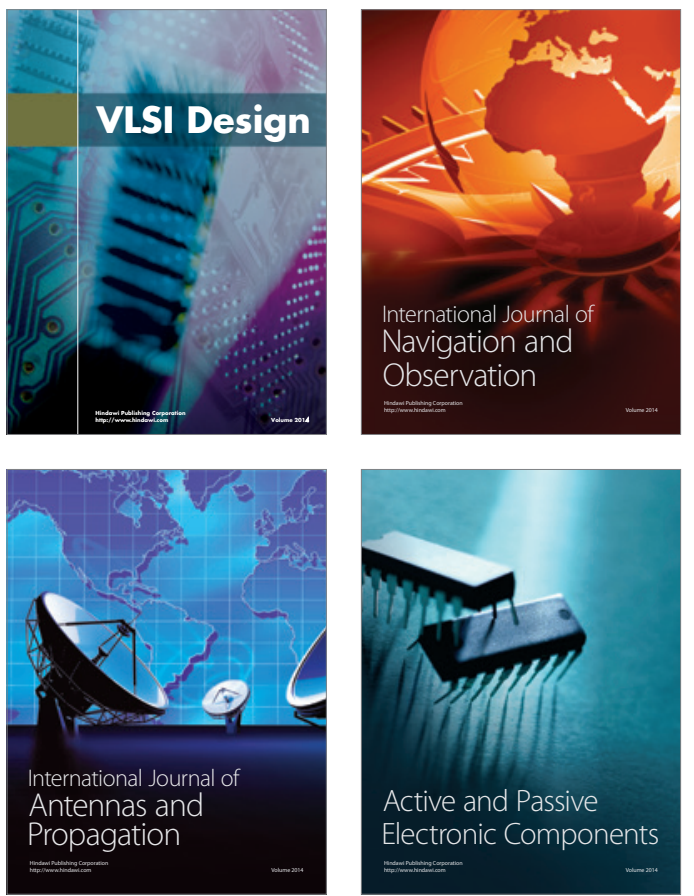
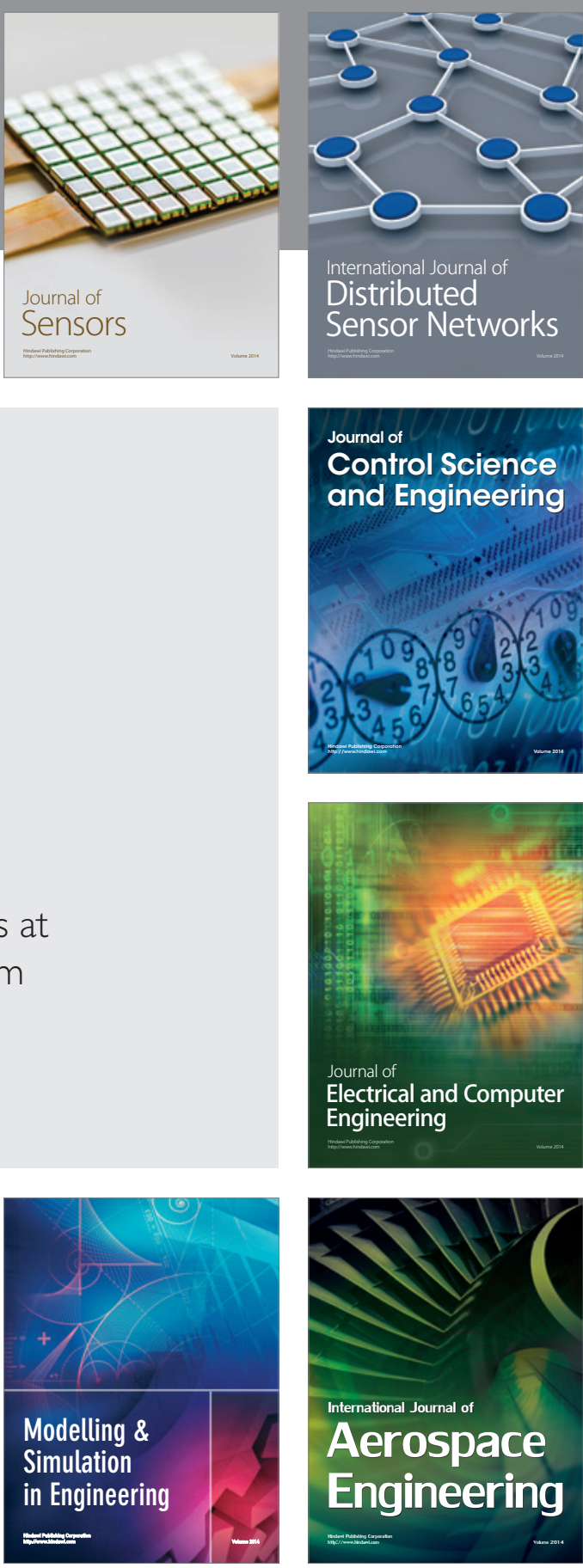

International Journal of

Distributed

Sensor Networks

Journal of

Control Science

and Engineering
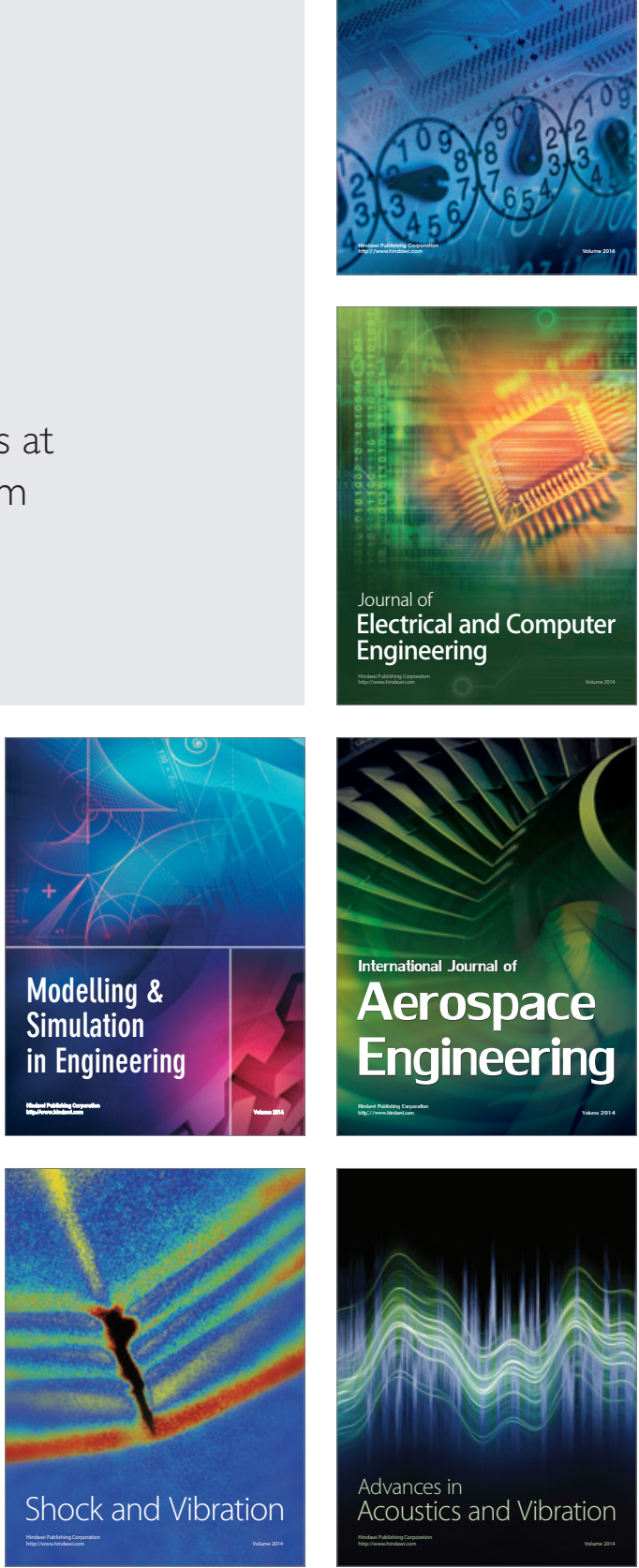